Rs: Does that mean that eventually most of the funds that the British government puts into research will go through European bodies?

ww: No. We should use subsidiarity here as much as anywhere: we should do at a European level only what needs to be done at that level.

\section{Coordinating medical research}

Rs: Can we talk specifically for a moment about medical research? Something that people are confused about is how exactly the MRC and the research and development arm of the NHS are going to work together.

ww: Firstly, I greatly welcome the development of a research and development capacity within the NHS. I think that's a major step forward. I suspect that it will mean that the NHS will begin to be a much more organised customer of the output of the MRC and other institutions. That might make Rothschild work in a way that it hasn't. I guess that Mike Peckham [NHS director of research and development] will be down towards the applied end, the end closer to patients, so that it will sort out better responsibilities. He should be doing a lot of development work, with the research council supporting the science base.

RS: Eventually the NHS research and development arm will have a bigger budget than the MRC. Will no money be taken away from the MRC? Will the whole pot for medical research be much larger?

ww: I don't think that Mike thinks that there will be any less money for the basic science base. I think that he's got his other frontier to watch-in that there's a lot of people around who may say that they are doing research but are not. Now that we have specific flows for research within the NHS it's important that those flows are not diverted into supporting ordinary service work.

RS: More and more research is being funded by medical charities. Does this mean that in some sense medical research is being privatised?

ww: I just think that the charities are a terrific extra national resource.

RS: Do you think that there need to be better mechanisms to coordinate the research funded by government and the charities?

ww: Yes, I do. That is also a role for this department.

Rs: Finally, do you think that you are the right person to be responsible for science in Britain?

ww: What a question. But, yes: I can't think of a job I'd rather have. It's a tremendous opportunity to set up this department and produce a white paper that might have a profound effect on British science.

\title{
The Tomlinson report and postgraduate medical education
}

\author{
J D Swales
}

This is the eighth article in our series looking at the issues highlighted by the Tomlinson report into London's health care and medical research and education.

Department of Medicine, University of Leicester, Leicester LE2 7 LX JD Swales, professor of medicine
The postgraduate hospitals of London grew up in the nineteenth century and offered a unique national specialist service. Since then specialist services have developed in undergraduate hospitals throughout Britain as well as in London, but the postgraduate hospitals have nevertheless preserved their high levels of staffing. Although numbers of medical posts in the provinces have grown, this has not been by redistribution of London posts but merely differential growth. The fact identified by Tomlinson-that Londoners are not receiving the most appropriate clinical care-is in fact the strongest argument for changing postgraduate medical education. Such education needs to be rooted first in clinical care, though Tomlinson underestimates the importance to education of such care being sited in a shared environment with strong scientific activity.

"A sharp remedy but a sure one" remarked Sir Walter Raleigh on contemplating the axe. Staff of London teaching hospitals surely share the former if not the latter sentiment on hearing of the radical surgery recommended by the Tomlinson report. Nevertheless, despite understandable anxiety it seems probable that at least some action will be taken along the lines proposed. If this is the case, there will clearly be important consequences not only for patient care but also for the other roles which hospitals play in teaching and research.

\section{Interwoven with patient care}

The first observation to make is that these activities are tightly interwoven. Clinical research and teaching cannot be divorced from patient care. If they could, the raison d'être of the teaching hospital would disappear, and medical schools could be removed to pleasant green field sites. This is an obvious point and it is regrettable that it has to be made, but it is often forgotten or ignored.

The sheer magnitude of the National Health Service as an operation and the complexity of its functions creates obstacles to change. Any attempt to correct one problem immediately has an impact elsewhere-for instance, on research, training, or manpower. There is

\section{"If clinical work has somehow become dissociated from teaching ... the primary aims of the institution have become confused."}

an unfortunate tendency to isolate problems in the face of such difficulties. Proposals are made to improve standards of care, training, or career structure. It is then pointed out that recommendations aimed at resolving one problem have an adverse impact elsewhere. Under the circumstances the status quo often appears the best of a series of unattractive options and nothing alters until a threshold of discontent is reached and rapid change is effected, often with damaging consequences.

I do not believe therefore that postgraduate education can be considered in isolation. It also should be axiomatic that patient care and well being are the primary purpose of the health service. Some might regard this statement as banal, others as wildly romantic, but it is a necessary truth.

Clinical teaching and research are important parts of 


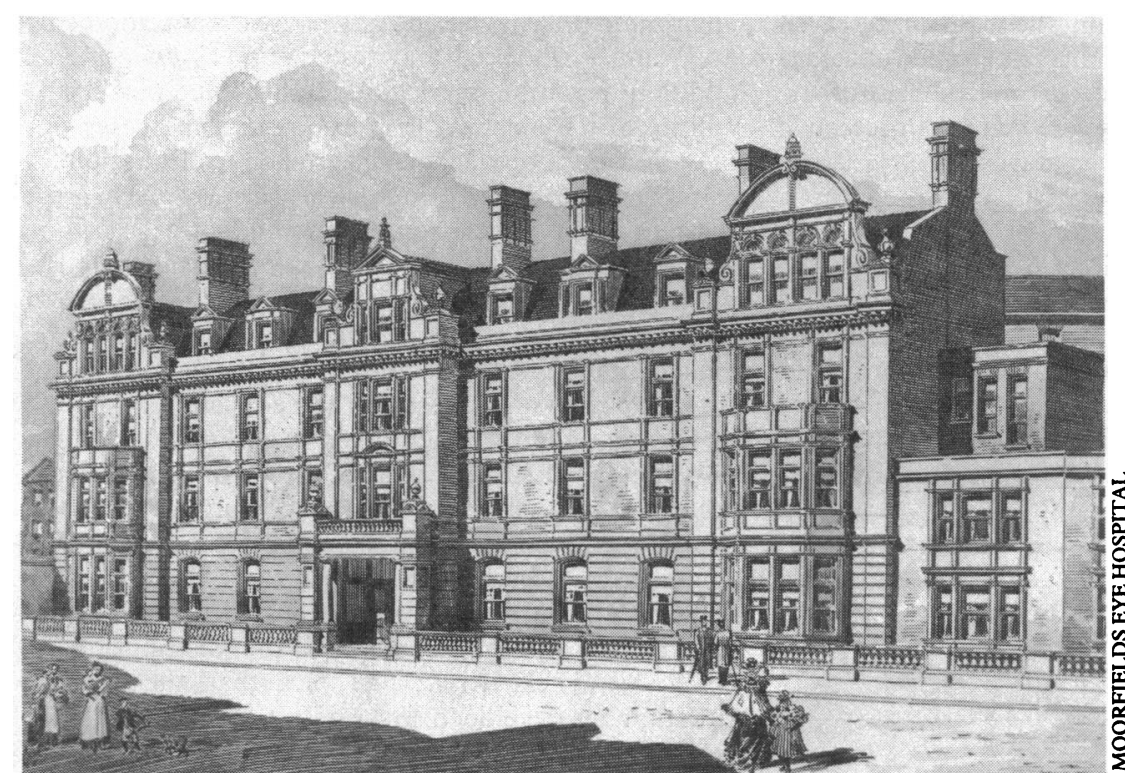

Specialist hospitals, like Moorfields, have been well endowed with junior doctors and consultants

clinical activity, although the benefits they produce are likely to be more long term. They are therefore more vulnerable. Since these activities make extra demands on the institutions where they are carried out, they require special support and protection. On the other hand, patients cannot be delivered like chemicals and laboratory animals to fulfil these objectives independently of the service which is offered. If clinical work has somehow become dissociated from teaching and research or fails to meet the needs of these activities, it is fair to conclude that the primary aims of the institution have become confused. To create an artificial pattern of clinical work is to ignore the primary purpose of the hospital-besides being expensive and unattractive for patients.

\section{Historical distortions}

Dainton has pointed to the dangers inherent in "secret gardens" where-for the best of motivesmembers of a profession decide behind high fences the way their obligations and duties should be discharged and set their own priorities.' This is no longer acceptable to either the government or the public, who demand accountability for the way their money is spent. Both will support the education of doctors and clinical research but not when the result is seen as inappropriate services and waste. We have entered an era when the expectations of medicine far exceed the resources available to meet these expectations. Needlessly high expenditure simply increases the shortfall.

It follows from this that if the conclusions of the Tomlinson inquiry ${ }^{2}$ (and for that matter the earlier King's Fund report $^{3}$ ) are correct and the clinical services of central London are inappropriate postgraduate training of doctors must also be deficient in some respects. Furthermore, the needs of postgraduate training cannot be used as a justification for maintaining inappropriate clinical services.

There is, however, an equally important consideration which Tomlinson does not emphasise. The historical distortions in clinical service are also observed independently in postgraduate medical education. The development of the specialist hospitals in the nineteenth century with no undergraduate teaching responsibilities created institutions which offered a unique national service and specialist experience. Like the undergraduate teaching hospitals, they have also been exceptionally well endowed with both consultants and more junior medical staff. To a large extent they have been sheltered from the redistribution of junior staff between London and the provinces which has taken place over the past decade. No doubt if we were starting afresh they would have been associated with universities elsewhere in the country, but history has determined otherwise and their position for the main part in central London compounds the London problem.

They are also the products of their age. For example, there is no specialist postgradute hospital dealing with the major medical problem of contemporary societythe care of the aged-and their contribution to this subject has been small. When they acted as national referral centres there was a strong argument for the junior doctor with specialist ambitions to spend a period working in them. Specialist services, grew up however, within the undergraduate hospitals elsewhere in Britain; and even in London undergraduate teaching hospitals compete in offering clinical specialist services in such specialties as cardiology, thoracic medicine, paediatrics, and neurology.

So far the special health authorities which manage the postgraduate hospitals have been afforded a (cash limited) protection from the rigors of the internal market, but the Tomlinson report proposes that this

\section{"There is no specialist postgraduate hospital dealing with the major medical problem of contemporary society..."}

should be ended. Even without this threat, however, their strength in the range of clinical experience they offer has been progressively eroded by the growth of services elsewhere.

The postgraduate specialist hospitals are argued still to offer unique experience in new developments at the frontiers of medical science. Here again, however, their pre-eminent role has been overtaken as their position as national referral centres has declined. It is difficult to see how it could have been otherwise. Now innovative work in the medical specialties is much more evenly dispersed in specialist units across Britain. The special health authorities still have their great international strengths: like all other teaching hospitals, they also have their manifest areas of weakness.

\section{High staffing levels}

The remaining argument in favour of their role as postgraduate educational institutions is undeniablethe very high staffing levels they enjoy. An argument based on this fact would seem to have a circular element to it, and in the light of the accumulation of junior clinical staff in some cases, would seem unconvincing (table I). The needs of clinical research are, of course, quite distinct and where posts are obtained in open

TABLE I-Senior registrar posts in each of the specialist postgraduate hospitals compared with total senior registrars in all hospitals in health service regions

\begin{tabular}{|c|c|c|c|c|c|}
\hline & \multicolumn{3}{|c|}{$\begin{array}{l}\text { Specialist postgraduate } \\
\text { hospital }\end{array}$} & \multirow[t]{2}{*}{$\begin{array}{l}\text { Average } \\
\text { Thames } \\
\text { region }\end{array}$} & \multirow[t]{2}{*}{$\begin{array}{l}\text { Average } \\
\text { non-London } \\
\text { region }\end{array}$} \\
\hline & Career & $M R C$ & $A M R C$ & & \\
\hline Paediatrics & 16 & 0 & 5 & $18 \cdot 5$ & $11 \cdot 2$ \\
\hline Neurology & 5 & 0 & 0 & $2 \cdot 5$ & 1.6 \\
\hline Ophthalmology & 24 & 0 & 0 & $4 \cdot 3$ & 6.0 \\
\hline \multirow{3}{*}{$\begin{array}{l}\text { Psychiatry } \\
\text { Cardiology/thoracic } \\
\text { medicine }\end{array}$} & 35 & 4 & 0 & 45.5 & 33.3 \\
\hline & 10 & 0 & 0 & 8.5 & 11.2 \\
\hline & & & & & \\
\hline
\end{tabular}

Data from Joint Planning Advisory Committee Report 1990-1.* AMRC = staff funded by members of the Association of Medical Research Charities. 
competition (as presumably in the case of research council or charitable awards) this is a proper unassailable token of merit. The same cannot be said of the other posts listed in table I, where vigorous protective mechanisms appear to have been at work.

What has happened hitherto is evident from a broader picture-the distribution of all medical staff between London and the regions. Some change in the ratio between London (including undergraduate and postgraduate hospitals) has occurred over the past decade, but this is wholly attributable to a more rapid increase in numbers of medical staff in the provinces: levels increased at both sites. The pattern has not therefore been one of redistribution-merely differential growth (table II).

TABLE II-Average numbers of hospital medical staff in London and nonLondon regions per 100000 population, together with percentage change in absolute numbers of staff between 1977 and 1988

\begin{tabular}{lcccc}
\hline & 1977 & 1982 & 1988 & $\%$ Change \\
\hline Average Thames region & 94 & 98 & 101 & 9 \\
Average non-London region & 74 & 84 & 91 & 26 \\
London postgraduate hospitals & - & - & - & 14 \\
\hline
\end{tabular}

Data from Office of Health Economics."

\section{High quality clinical service}

I do not wish to appear negative. The criteria for a successful setting for postgraduate medical education should be straightforward. The fundamental necessity must remain a high quality clinical service for adequate numbers of patients. This is not, of course, sufficient. There have to be additional staff so that there is time for critical discussion, supervision, and teaching. The environment has to be one in which new developments are being introduced and tested, not as an optional addition to routine service but an accepted part of the culture of the teaching institution. In some cases this may include a broader perspective in such disciplines as epidemiology or biomedical science. My great concern in the Tomlinson recommendations is that he proposes removing the environment crucial to postgraduate teaching even further from its ultimate area of application-patient management. I recognise the logistic argument but regret the inevitable outcome of such a policy both for research and education.

The argument for action on the clinical side is a pressing one. I suspect that the needs of postgraduate education and clinical research will duly be exhibited as arguments for resisting Tomlinson's recommendations. In fact their needs reinforce the argument for change. A historically fixed distribution of resources and people no longer matches the distribution of activity and expertise. The fact that the present situation has developed so far despite so many calls for action is a tribute not only to the high fence which has surrounded the secret garden but also to the protection given to pleasant and quiet groves within that garden.

1 Dainton F. Opening the secret garden-keynote address. In: L'Etang $\mathrm{H}$, ed. Health care provision under financial constraint: a decade of change. London Royal Society of Medicine, 1990:7-11 (International Symposium Series No 171 .

2 Enquiry into London's Health Service, Medical Education and Research. Report. London: HMSO, 1992 (Tomlinson report).

3 King's Fund Commission on the Future of London's Acute Health Services. London Health Care 2120: Changes in the future of services in the capital. London Health Care 2120:
London: King's Fund, 1992 .

4 Joint Planning Advisory Committee. Report for the year 1990-91. London: NHS Management Committee, 1992.

5 Compendium of health statistics. 7 th ed. London: Office of Health Economics, 1989.

\section{Countdown to Community Care}

\section{Moving ahead-community care in Gwent}

\section{Roger Robinson}

This is the third in a series of articles looking at the forthcoming changes to community care
British Medical Journal, London WC1H 9JR

Roger Robinson, associate editor

$B M 71993 ; 306: 44-7$
The new rules and recommendations for community care come into force on 1 April. Two previous articles in this series described the reforms which the new law expects $^{12}$ : the next four will describe how different places in the United Kingdom are preparing for change. The first of these looks at Gwent in Wales.

Gwent is a county of geographical and social variety. It includes Blaenau Gwent in the north, an old mining valley area whose pits had all shut down before the recent wholesale proposals for closure; Newport in the south, with some inner city problems; and Monmouth in the east, a large sparsely populated area of rich farming country.

Gwent has had a head start in preparing for change. In many ways it has been progressive in planning and providing community care. For the past nine years the county has followed the All-Wales Strategy for Mental Handicap (this term is still used instead of learning disability in the title of the scheme), ${ }^{3}$ setting up a community based system of care with assessment and planning centred on individual needs. The All-Wales Strategy for Mental Illness has been implemented more recently. ${ }^{4}$ Planning is easier than in many counties because the boundaries of local authorities and health authorities coincide. There is a strong and active voluntary sector. Finally, the Welsh Office is responsible for both health and social services.

I spent three days in Gwent talking to some of the people who are planning the new way of community care or who will be affected by it. What follows is a series of impressions which do not necessarily apply throughout the county, or represent generally the attitudes of each interested group, but do indicate what some of those involved in the new plans are thinking and doing.

\section{The planners}

SOCIAL SERVICES

"This is the biggest change to have hit social services departments since they started," says Paul Meredith, principal planning officer of Gwent County Council's social service department. $\mathrm{He}$ is in no doubt of the scale or importance of the changes in community care, nor of their benefit to the users in the long run. He distinguishes, however, between those statutory changes which must happen by 1 April and those, such as the introduction of care management, which will come in more gradually.

Of the statutory changes, the one causing most general anxiety is the transfer to social services of the social security funds that are now spent on residential and nursing home care. Paul Meredith thinks that this change will force difficult decisions in Gwent, where there has been a huge increase recently in private nursing home placements of elderly people funded by social security. Nearly four fifths of private residential provision in Gwent is in nursing homes, compared 